\title{
Anchoring Au Nanoparticles onto ZnO Nanowires by Heteroepitaxy
}

\author{
J. X. Liu ${ }^{1,2}$, Y. D. Huang ${ }^{2}$ and J. Y. Liu ${ }^{1}$
}

${ }^{1}$ Department of Physics, Arizona State University, Tempe, Arizona 85287, USA

${ }^{2}$ College of Chemical Engineering and Technology, Harbin Institute of Technology, Harbin 150001, China

Supported Au nanoparticles (NPs) with sizes $<5 \mathrm{~nm}$ have been proved to be highly active for many important catalytic reactions [1]. The development of thermally stable supported Au NP catalysts, however, is challenging. Unlike other noble metals, Au NPs or clusters sinter rapidly during catalytic reactions at elevated temperatures or even under long-term storage [2]. There are many approaches to stabilizing supported metal NPs or clusters [3]. Our approach to developing sintering-resistant supported metal nanocatalysts is to anchor the active metal NPs to well-defined support surfaces by heteroepitaxial growth. We report here the synthesis of stable $\mathrm{Au} / \mathrm{ZnO}$ nanostructured catalysts by epitaxially growing $\mathrm{Au}$ NPs onto the flat and clean surfaces of $\mathrm{ZnO}$ nanowires (NWs), the detailed atomic scale characterization of the fabricated catalysts, and their stability during the $\mathrm{CO}$ oxidation reaction.

$\mathrm{ZnO} \mathrm{NWs}$ were fabricated by a thermal evaporation-condensation method in a high-temperature tube furnace. The $2 \mathrm{wt} \% \mathrm{Au} / \mathrm{Zn}$ Onanocatalysts were prepared by a deposition-precipitation method. The $\mathrm{ZnO}$ $\mathrm{NW}$ and powder supported $\mathrm{Au}$ catalysts are labeled as $\mathrm{Au} / \mathrm{ZnO}-\mathrm{NW}$ and $\mathrm{Au} / \mathrm{ZnO}-\mathrm{P}$, respectively. The final catalysts were obtained by calcining the precursors at $400^{\circ} \mathrm{C}$ for 4 hours. The $5 \mathrm{wt} \% \mathrm{Au} / \mathrm{ZnO}$ nanocatalysts calcined at $600^{\circ} \mathrm{C}$ were synthesized for XRD analysis. The catalytic performances of the prepared samples for $\mathrm{CO}$ oxidation were evaluated in a fixed-bed plug-flow reactor. Powder X-ray diffraction (XRD) patterns were taken on a PANalyticalX'pert PRO MRD X-ray diffractometer using Cu Ka radiation. The JEOL JEM-ARM200F aberration-corrected scanning transmission electron microscope (STEM), with a nominal image resolution of $0.08 \mathrm{~nm}$ in the high-angle annular dark-field (HAADF) imaging mode, was used to investigate the structure of the $\mathrm{Au} / \mathrm{ZnO}$ catalysts.

The XRD pattern for the $5 \mathrm{wt} \% \mathrm{Au} / \mathrm{ZnO}-\mathrm{NW}-600$ catalyst (Fig. 1) showed that the ZnO NWs possess a wurtzite structure. Diffraction peaks from the Au NPs were visible and no alloy phases were found. Fig. 2a, a HAADF image of a representative $\mathrm{ZnO} \mathrm{NW}$ in the $\mathrm{Au} / \mathrm{ZnO} \mathrm{NW}-400$ catalyst, shows 2-4 nm gold NPs epitaxially grown onto the $\mathrm{ZnO}\{10-10\}$ nanoscale facets. The digital diffractogram (the inset in Fig. 2a) displays spots for both the Au NPs (indicated by the white circles) and the ZnO NW, oriented close to the [11-20] zone axis. The Au NPs grew epitaxially onto the ZnO $\{10-10\}$ surfaces with an epitaxial relationship as $\mathrm{ZnO}$ [11-20] (-1101) //Au [110] (1-1-1). Fig. 2b shows a high magnification HAADF image, clearly revealing the atomic arrangement of the Au atoms and the interfacial structures between the $\mathrm{Au}$ NPs and the ZnO NW support. The Au NPs are highly faceted exposing predominantly $\{111\}$ facets and some $\{100\}$ facets. In order to understand the observed epitaxial growth of Au NPs on ZnO NWs, we adapted the model of domain-matching epitaxy [4]. The Au (111) planes matches with $\mathrm{ZnO}(0001)$ with about $10 \%$ misfit and a tilt angle of about $6^{\circ}$ between the $\mathrm{Au}(111)$ and the $\mathrm{ZnO}(0001)$ planes. However, if we consider a domain containing five layers of $\mathrm{Au}$ atoms and four layers of $\mathrm{Zn}$ atoms of $\mathrm{ZnO}$, the mismatch becomes much smaller, favoring epitaxial growth with the addition of a dislocation. Such epitaxially anchored Au NPs should exhibit high structural stability during catalytic reactions. A 20-hour test for $\mathrm{CO}$ oxidation at $150^{\circ} \mathrm{C}$ was used to evaluate the stability of the $\mathrm{Au} / \mathrm{ZnO}-\mathrm{NW}-400$ catalyst (Fig. 3). A similarly synthesized $\mathrm{Au} / \mathrm{ZnO}-\mathrm{P}-400$ was also tested as a control. Fig. 3 clearly demonstrates that the 
$\mathrm{Au} / \mathrm{ZnO}-\mathrm{NW}-400$ catalyst is much more stable than the $\mathrm{Au} / \mathrm{ZnO}-\mathrm{P}-400$ catalyst, illustrating the anchoring of Au nanoparticles by epitaxial growth. It is expected that the stability of the epitaxially grown Au NPs will become more prominent at higher reaction temperatures. Optimization of the catalyst synthesis processes and applications to other types of catalytic reactions will be discussed [5].

\section{References:}

[1] G. Bond and D. Thompson, Gold Bulletin 33 (2000) p. 41.

[2] M. Haruta, CATTECH 6 (2002) p. 102.

[3] J. Liu, Chem Cat Chem3 (2011) p. 934.

[4] J. Narayan, Journal of Applied Physics 93 (2003) p. 278.

[5] This research was funded by Arizona State University. We gratefully acknowledge the use of facilities within the LeRoy Eyring Center for Solid State Science at Arizona State University.
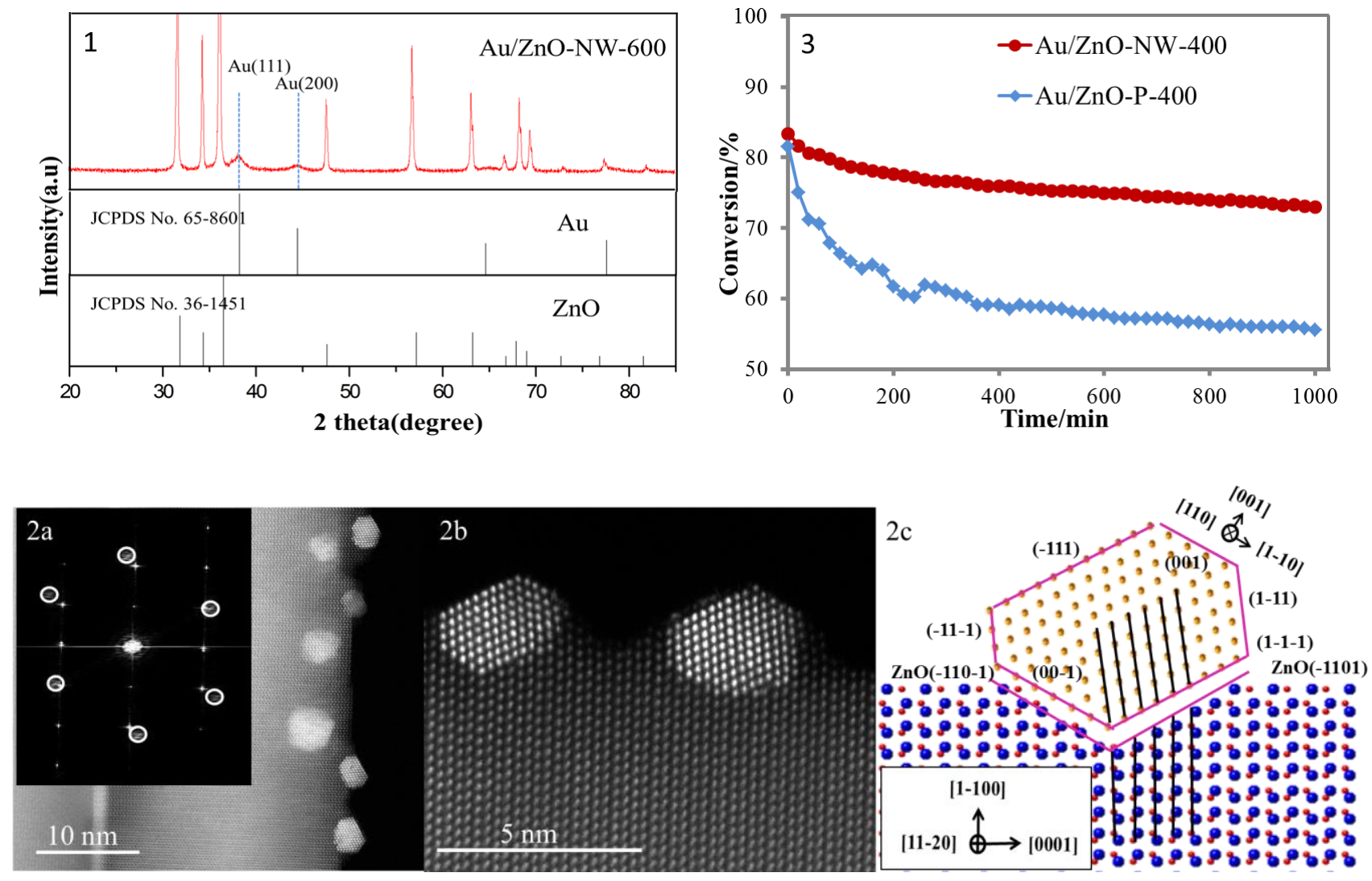

Figure 1.XRD pattern of $5 \mathrm{wt} \% \mathrm{Au} / \mathrm{ZnO} \mathrm{NW}$ after $4 \mathrm{~h} @ 600^{\circ} \mathrm{C}$ in air shows Au and wurtzite $\mathrm{ZnO}$.

Figure 2.Low (a) and high (b) magnification HAADF images of $2 \mathrm{wt} \% \mathrm{Au} / \mathrm{ZnO} \mathrm{NW}$ catalyst and (c) schematic diagram illustrating the relationship between the faceted $\mathrm{Au}$ NPs and the $\mathrm{ZnO} \mathrm{NW}$.

Figure 3. $\mathrm{CO}$ conversion as a function of time at $150^{\circ} \mathrm{C}$ on $2 \mathrm{wt} \% \mathrm{Au} / \mathrm{ZnO}-\mathrm{NW}$ and $2 \mathrm{wt} \% \mathrm{Au} / \mathrm{ZnO}-\mathrm{P}$ catalysts for $\mathrm{CO}$ oxidation reaction $\left(1 \mathrm{vol} \% \mathrm{CO}+1 \mathrm{vol} \% \mathrm{O}_{2}\right.$ and $\mathrm{He}$ balance, gas hourly space velocity of $\sim 40,000 \mathrm{ml} \mathrm{g}^{-1}$ cat $\mathrm{h}^{-1}$ ). 